\title{
COVID-19 vaccine development: Time to consider SARS-CoV-2 challenge studies?
}

\author{
G.O. Schaefer, C. Tam, J. Savulescu, T.C. Voo
}

As the world struggles to control the COVID-19 pandemic, a group of researchers have recently proposed a bold agenda: developing a vaccine using a 'challenge study'. ${ }^{1}$ The idea is to deliberately infect individuals in order to accelerate eventual licensure of an effective vaccine.

A version of this idea is already in practice. A UK group is currently conducting a challenge study using related coronaviruses that cause milder disease. ${ }^{2}$ However, major limitation of this approach is that results using other coronaviruses might not directly apply to SARS$\mathrm{CoV}-2$, the coronavirus that causes COVID-19. So, a further question must be asked should challenge studies specifically using SARS-CoV-2 therefore be considered?

Here, we outline why this prospect should be taken seriously, and examine the drawbacks and caveats. We believe that this option should at least be 'on the table', although further analysis is needed to establish whether such a study is scientifically and ethically justifiable. If (as some characterise it) efforts against COVID-19 are akin to a war, ${ }^{3}$ and likely a longdrawn one, then by the same analogy we should carefully consider what "weapons" can and should be deployed.

Some have characterised a proposed challenge study as a loosening or lowering of standards for research. ${ }^{4}$ But on the contrary, when these studies are well designed and follow established challenge study procedures, they can be ethically sound and safe for participants. ${ }^{5}$

\section{Why challenge studies are done}

The first known vaccine challenge study was published in 1798 when Edward Jenner exposed people who had been infected with the cowpox virus to smallpox. ${ }^{6}$

Since then challenge studies have aided the development of disease treatments and vaccines for malaria, influenza, typhoid fever, cholera and dengue. ${ }^{7}$ Because these studies happen in a controlled environment, it is easier for researchers to study the natural progression of the disease than it would be in the field. In traditional vaccine trials, a high-risk population is usually selected, but not everyone in that population is necessarily exposed, and risk may not be evenly distributed; people's exposure to infection may vary, and not everyone may be infected during the trial. This means that large trials with substantial follow-up time to accumulate enough cases are needed to test vaccine efficacy. A challenge study guarantees uniform exposure, so potentially can be done faster and with fewer participants. This approach 
could speed up vaccine development by eliminating ineffective candidates early on and accelerating field trials of the most promising vaccines.

\section{The case for SARS-CoV-2 challenge studies}

The urgency of the current pandemic gives substantial weight to a challenge study. As of 21 March 2020, more than 820,000 COVID-19 cases and 40,000 deaths have been reported globally. ${ }^{8}$ Those numbers will continue to rise, and there is great uncertainty concerning how many cases, hospitalisations and deaths will eventually occur and how long the pandemic will last. In addition, the pandemic is expected to trigger a global recession ${ }^{9}$ that will in turn further negatively impact the health and well-being of individuals around the globe. According to one estimate, 25 million jobs will be lost worldwide; ${ }^{10}$ according to another, 11 million will be impoverished. ${ }^{11}$

SARS-CoV-2 challenge studies could accomplish three things: study the clinical progression, develop effective vaccines and test candidate therapies. The latter is perhaps less imperative, as therapeutic trials are already taking place in existing patients. ${ }^{12}$ To study clinical progression, volunteers challenged with standardized doses of virus would be observed to find out what proportion develop symptoms, how much virus it takes to cause disease, how long it takes for infected individuals to develop symptoms (the incubation period), how long individuals are infectious for, and what biomarkers are associated with more severe disease or a more effective immune response. These observations could help answer currently unresolved questions and aid policy decisions, such as whether quarantine durations are adequate, what criteria should be used to ensure that discharged patients are not infectious, the extent to which truly asymptomatically infected individuals are infectious, or whether recovered patients can later be re-infected.

Additionally, candidate vaccines that have satisfied phase I safety and phase IIa dosage trials could be administered to volunteers who are subsequently challenged with the virus as part of a phase IIb trial to see how well the vaccine protects them as compared with a placebo or suitable alternative. While promising vaccines must eventually undergo large-scale testing in at-risk communities, the process of assessing candidate vaccines prior to large phase III trials can be substantially accelerated by challenge studies. ${ }^{1,13}$ Having a vaccine ready for market even a few weeks sooner than would otherwise be possible would not only save many lives and relieve pressure on strained health systems, but would likely have global social benefits, by allowing countries and economies to open up and begin to return to normalcy that much earlier.

\section{Ethical concerns for SARS-CoV-2 challenge studies}

The most immediate concerns with any challenge study are the substantial risks to participants and wider society. Estimates of COVID-19 mortality and serious complications 
vary, with current figures from China putting the symptomatic case fatality rate at about $1.4 \% .^{14,15}$ There is a clear age effect, with substantially lower mortality in younger individuals. ${ }^{16}$ Any challenge study would therefore likely recruit younger individuals, to minimize the risk of adverse outcomes from SARS-CoV-2 challenge. A downside is that results in young healthy adults may not generalize to older individuals and those with comorbidities who would most benefit from effective vaccines. However, this approach could accelerate progression of promising candidate vaccines to Phase III trials that would include high-risk groups.

Substantial monetary compensation is typically offered for challenge studies; the ongoing coronavirus challenge study will pay participants GBP3,500. ${ }^{2}$ Some hold that such compensation should only be used to offset time and inconvenience, ${ }^{17}$ while others maintain it can further compensate for the risks and burdens of participation. ${ }^{5}$ In either case, it is generally accepted that the compensation itself cannot justify the risks and burdens imposed; justification for a SARS-CoV-2 challenge study should be based solely on social benefits accrued.

Even with appropriate participant selection criteria to minimize harms, a fair compensation mechanism, and high-quality safety monitoring, the physical risks of a challenge study cannot be dismissed. How much risk should we allow individuals to undertake? Wartime analogies imply quite a lot; if individuals can volunteer to risk their lives on the battlefield, why not allow them to do so in the global fight against COVID-19? ${ }^{18}$

A key difference is the potential negative externalities of a challenge study, as SARS-CoV2 is highly infectious. Risk of community spread from participants can be mitigated by isolation and standard infection control measures during challenge studies. Participants would maintain their right to withdraw challenge studies, ${ }^{19}$ but prevailing isolation and quarantine laws would apply to separate infected participants from the community even if they refused further observation and testing in a research setting.

However, quarantine efforts are not fool proof. The possibility always exists of infecting research team members, even when using adequate personal protective equipment, or of individuals being infectious for longer than previously believed. But if research is key to pandemic response then researchers, like healthcare workers, should be allowed to bear the risks of conducting a challenge study as part of frontline work. ${ }^{20}$

One of the most serious impacts of the COVID-19 pandemic is the incredible burden on healthcare systems. A challenge study would potentially divert resources - in the form of medical personnel, equipment and other infrastructure - away from treatment centres and public health efforts where those are sorely needed. In addition, ill participants might have a rightful claim to prioritisation for critical care resources like ventilators, analogous to the priority proposed for healthcare workers in light of the risks they undertake. ${ }^{21}$ Such 
prioritisation might come at the cost of non-participants, with consequent negative health effects.

To ensure fairer allocation of scarce resources and maximization of medical benefits, all patients needing critical care could be assessed equally based on short- and long-term survival prospects, with priority given to research participants only if they are equivalent to other patients in terms of survival probability and prognosis. The justification is based on reciprocity, recognising the social contribution and significant personal risks resulting from participation in challenge studies. However, any such prioritization would be subject to prevailing legal norms in the jurisdictions where the challenge study takes place. ${ }^{22}$

Due to the substantial risks and potential distorting effects of sizeable monetary compensation, the informed consent process should require adequate information to be conveyed and participants assessed to ensure they truly understand what they are undertaking. ${ }^{5}$ Box 1 details the types of information that it would be essential for potential participants to understand. This is not an exhaustive list, and the consent process would of necessity be very detailed, but is meant to outline pieces of information that will be most relevant to participants' decisions.

Box 1: Essential information in the informed consent process for a SARS-CoV-2 challenge study

\begin{tabular}{|l|l|}
\hline $\begin{array}{l}\text { Information } \\
\text { and mortality }\end{array}$ & Details \\
\hline $\begin{array}{l}\text { Nature of COVID-19 and contracting COVID-19 } \\
\text { treatment }\end{array}$ & $\begin{array}{l}\text { Based on existing observational data, broken down to } \\
\text { the extent feasible by age range and other relevant } \\
\text { factors. Uncertainties around these estimates should } \\
\text { be conveyed, along with the possibility that the rates } \\
\text { among challenge study participants will substantially } \\
\text { differ. }\end{array}$ \\
\hline Prospects for success & $\begin{array}{l}\text { Spectrum of disease presentation and severity, } \\
\text { prognosis, and type of symptomatic treatments and } \\
\text { supportive care available (e.g. invasive mechanical } \\
\text { ventilation for critically ill cases) }\end{array}$ \\
\hline $\begin{array}{l}\text { Explanation of the study's aims and prospects for } \\
\text { benefiting society, of sufficient derail that } \\
\text { participants can adequately assess whether the social } \\
\text { value of the study is worth its substantial personal } \\
\text { risks. In the interest of transparency, this should } \\
\text { include forthright information on the very real } \\
\text { possibility that candidate vaccines will fail, and the } \\
\text { minimum duration for the development of a safe and } \\
\text { effective vaccine }\end{array}$ \\
\hline
\end{tabular}




\begin{tabular}{|c|c|}
\hline Study procedures & $\begin{array}{l}\text { Length of stay, type of facility, amenities available, } \\
\text { visitation from family possible and alternatives, } \\
\text { follow-up procedures, etc. }\end{array}$ \\
\hline $\begin{array}{l}\text { Risks of experimental } \\
\text { vaccines/treatments }\end{array}$ & $\begin{array}{l}\text { Phase I safety data should already be available when } \\
\text { a challenge study commences. }\end{array}$ \\
\hline Potential for re-infection & $\begin{array}{l}\text { Information on what is known about the duration of } \\
\text { immunity, both from natural infection and from } \\
\text { vaccination, acknowledging that there could be a risk } \\
\text { of re-infection, even if patients receive the vaccine }\end{array}$ \\
\hline $\begin{array}{l}\text { Requirements for mandatory } \\
\text { isolation }\end{array}$ & $\begin{array}{l}\text { Participants may withdraw from the study at any } \\
\text { time, but would still have to remain in isolation per } \\
\text { local policies. Data gathered up to point of } \\
\text { withdrawal may be retained if local laws allow so, } \\
\text { especially in light of the substantial public interest in } \\
\text { retaining as full and unbiased a dataset as possible. }\end{array}$ \\
\hline $\begin{array}{l}\text { Priority for treatment, or lack } \\
\text { thereof }\end{array}$ & $\begin{array}{l}\text { Depending on whether such priority is agreed to by } \\
\text { relevant local healthcare institutions, with the caveat } \\
\text { that such policies are outside the control of the } \\
\text { research team and could be subsequently changed. }\end{array}$ \\
\hline Compensation & $\begin{array}{l}\text { Including information on whether payment will be } \\
\text { pro-rated in case of early withdrawal. }\end{array}$ \\
\hline Post-trial entitlements & $\begin{array}{l}\begin{array}{l}\text { E.g., access to future vaccines or experimental } \\
\text { therapies }\end{array} \\
\end{array}$ \\
\hline Alternatives to participation & $\begin{array}{l}\text { Other options, if available, to help fight COVID-19: } \\
\text { e.g., participation in Phase I clinical trials for } \\
\text { COVID-19 treatment and non-challenge vaccine } \\
\text { trials; social distancing; good hygiene/frequent hand- } \\
\text { washing }\end{array}$ \\
\hline
\end{tabular}

Given the risks to participants, SARS-CoV-2 challenge studies would need to demonstrate very substantial social value before proceeding. Arguably, this bar might already be met given the high death toll and severe disruption caused by the pandemic. For comparison, during the 2016 Zika virus epidemic, a challenge study was considered but ultimately rejected by a National Institutes of Health ethics panel, due to concerns about participant safety, third-party harms and social value. ${ }^{23}$ The circumstances of COVID-19 are substantially different and more globally devastating. Challenge studies are therefore more justifiable and should be given serious consideration as the human toll of the COVID-19 pandemic continues to grow. 
Works cited:

1 Eyal N, Lipsitch M, Smith PG. Human challenge studies to accelerate coronavirus vaccine licensure. The Journal of Infectious Diseases 2020; published online March 31. DOI:10.1093/infdis/jiaa152.

2 Roland D. Wanted: People Willing to Get Sick to Find Coronavirus Vaccine. The Wall Street Journal. 2020; published online March 19.

https:/www.wsj.com/articles/wanted-people-willing-to-get-sick-to-find-coronavirusvaccine-11584615600.

3 Chotiner I. Inside France's "Public-Health War" Against the Coronavirus. The New Yorker. 2020; published online March 19. https://www.newyorker.com/news/q-anda/inside-frances-public-health-war-against-the-coronavirus (accessed March 22, 2020).

4 Whipple T. Loosen rules 'to speed up hunt for coronavirus vaccine'. The Times. 2020; published online March 26. https://www.thetimes.co.uk/article/loosen-rules-to-speedup-hunt-for-coronavirus-vaccine-vv5fhczm7.

5 Bambery B, Selgelid M, Weijer C, Savulescu J, Pollard AJ. Ethical Criteria for Human Challenge Studies in Infectious Diseases. Public Health Ethics 2016; 9: 92-103.

6 Morabia A. Edward Jenner's 1798 report of challenge experiments demonstrating the protective effects of cowpox against smallpox. James Lind Library Bulletin:

Commentaries on the history of treatment evaluation 2010.

https://www.jameslindlibrary.org/articles/edward-jenners-1798-report-of-challengeexperiments-demonstrating-the-protective-effects-of-cowpox-against-smallpox/.

7 Cohen J. Studies that intentionally infect people with disease-causing bugs are on the rise. Science 2016; published online May 18. DOI:10.1126/science.aaf5726.

8 World Health Organization. Coronavirus disease 2019 (COVID-19) Situation Report 72. 2020 https://www.who.int/docs/default-source/coronaviruse/situationreports/20200321-sitrep-61-covid-19.pdf (accessed March 22, 2020).

9 Reuters. Global economy already in recession on coronavirus devastation. The Straits Times. 2020; published online March 20.

https://www.straitstimes.com/business/economy/global-economy-already-in-recessionon-coronavirus-devastation (accessed March 22, 2020).

10ILO News. Almost 25 million jobs could be lost worldwide as a result of COVID-19, says ILO. https://www.ilo.org/global/about-theilo/newsroom/news/WCMS_738742/lang--en/index.htm (accessed March 22, 2020).

11 The World Bank. East Asia and Pacific: Countries Must Act Now to Mitigate Economic Shock of COVID-19. https://www.worldbank.org/en/news/press- 
release/2020/03/30/east-asia-and-pacific-countries-must-act-now-to-mitigateeconomic-shock-of-covid-19 (accessed April 2, 2020).

12Cao B, Wang Y, Wen D, et al. A Trial of Lopinavir-Ritonavir in Adults Hospitalized with Severe Covid-19. N Engl J Med 2020; : NEJMoa2001282.

13 Balasingam S, Wilder-Smith A. Randomized controlled trials for influenza drugs and vaccines: a review of controlled human infection studies. International Journal of Infectious Diseases 2016; 49: 18-29.

$14 \mathrm{Wu}$ JT, Leung K, Bushman M, et al. Estimating clinical severity of COVID-19 from the transmission dynamics in Wuhan, China. Nat Med 2020; published online March 19. DOI:10.1038/s41591-020-0822-7.

15 Verity R, Okell LC, Dorigatti I, et al. Estimates of the severity of COVID-19 disease. Epidemiology, 2020 DOI:10.1101/2020.03.09.20033357.

16CDC COVID-19 Response Team, CDC COVID-19 Response Team, Bialek S, et al. Severe Outcomes Among Patients with Coronavirus Disease 2019 (COVID-19) United States, February 12-March 16, 2020. MMWR Morbidity and Mortality Weekly Report 2020; 69. DOI:10.15585/mmwr.mm6912e2.

17Council for International Organizations of Medical Sciences, World Health Organization. International ethical guidelines for health-related research involving humans. 2016.

18Savulescu J. Science wars--How much risk should soldiers be exposed to in military experimentation? Journal of Law and the Biosciences 2015; 2: 99-104.

19Fernandez Lynch $\mathrm{H}$. The right to withdraw from controlled human infection studies: Justifications and avoidance. Bioethics 2020; published online Jan 24. DOI:10.1111/bioe.12704.

20WHO Working Group on Ethics \& COVID-19. Ethical standards for research during public health emergencies: Distilling existing guidance to support COVID-19 R\&D. World Health Organization, 2020 https:/www.who.int/blueprint/prioritydiseases/key-action/liverecovery-save-of-ethical-standards-for-research-during-publichealth-

emergencies.pdf?ua $=1 \&$ fbclid=IwAR1Dt4p1f73uJzxZbpqb1fQ6uJvFA86Sc_voXwI8TI BEX0p5DPy_JE5Ut8 (accessed March 22, 2020).

21 Emanuel EJ, Persad G, Upshur R, et al. Fair Allocation of Scarce Medical Resources in the Time of Covid-19. 2020; published online March 23. https://www.nejm.org/doi/full/10.1056/NEJMsb2005114. 
22Sokol D, Gray B. Should we give priority care to healthcare workers in the covid-19 pandemic? BMJ Opinion. 2020; published online April 1.

https://blogs.bmj.com/bmj/2020/04/01/should-we-give-priority-care-to-healthcareworkers-in-the-covid-19-pandemic/ (accessed April 2, 2020).

23Shah SK, Kimmelman J, Lyerly AD, et al. Ethical Considerations for Zika Virus Human Challenge Trials. 2017

https://www.niaid.nih.gov/sites/default/files/EthicsZikaHumanChallengeStudiesReport 2017.pdf. 